\title{
Aspectos da Forma Narrativa em Estória do ladrão e do papagaio, de Luandino Vieira
}

Aspects of the Narrative Form in Estória do ladrão e do papagaio, by Luandino Vieira

$\underline{\underline{\text { Fábio Salem Daie }}}$ 
RESUMO: O presente artigo analisa aspectos do conto "Estória do ladrão e do papagaio", de Luandino Vieira, com foco em dois eixos centrais: o primeiro diz respeito à presença da estrutura colonial portuguesa na composição de sua própria estrutura textual; o segundo oferece justamente o vetor oposto, revelando-se em elementos que tensionam os limites sociais e ideológicos colocados pelo imperialismo. O intuito é estabelecer como ambas as dimensões contribuem para a qualidade estética da narrativa, em que uma das características mais importantes é a coesão interna.

PALAVRAS-CHAVE: Luandino Vieira; Luuanda; contos; forma narrativa; ideologia

ABSTRACT: This article analyzes aspects of the tale "Estória do ladrão e do papagaio", by Luandino Vieira, focusing on two central axes: the first concerns the presence of the Portuguese colonial structure in the composition of its own textual structure; the second offers just the opposite vector, revealing itself in elements that stress the social and ideological limits posed by imperialism. The aim is to establish how both dimensions contribute to the aesthetic quality of the narrative, in which one of the most important characteristics is its internal cohesion.

KEYWORDS: Luandino Vieira; Luuanda; short-stories; narrative form; ideology 
Em Luanda, início da década de 1960, Lomelino dos Reis - Dosreis para os amigos, ex-Loló para as mulheres - é branco (ou seja, tem a cor certa na cidade), mas é cabo-verdiano, o que coloca em suspeição a sua boa-fé e conduta local; casado e com dois filhos, é arrimo de família, condição prezada pela parte católica e dominante da sociedade luandense e, sobretudo, pelo chefe de polícia. Sendo "mais- velho", Lomelino é respeitado no musseque. Tem, contudo, dificuldade de se integrar na cidade baixa: pese a cor de pele correta, "falar bem-bem português não podia, o exame da terceira é que estava lhe tirar agora e por isso não aceitava falar um português de toda a gente, só queria falar o mais superior" (VIEIRA, 1982, p. 44) ${ }^{2}$. O “mais superior”, claro está, é o seu quimbundo.

Amigo de Lomelino, Garrido Fernandes é um mulato esbranquiçado, porém mulato. Seus olhos azuis e os cabelos "curtos quase louros" (p. 94) (de algum pai branco desconhecido) são um bom sinal, embora, por vezes, pesem nos olhos dos amigos. Chamado de Kam'tuta (que significa "coxo" e, tudo indica, de nascença), de garrido (que significa alegre, vistoso, forte) ele pouco tem: Garrido não pode garrir. Branco-mulato, a infelicidade da perna o arrastou, neste mundo de homens e raças superiores, para o chão da existência, onde Kam'tuta peleja, a ombreadas, com animais. O papagaio Jacó, que lhe arrebata a negra Inácia, é seu inimigo e é seu outro. Nas palavras de Antonio Candido sobre os kam'tutas que Graciliano pôs em Vidas Secas, "cada um desses desgraçados, na atrofia da sua rusticidade, se perscruta, se apalpa, tenta compreender, ajustando o mundo à sua visão - de homem, de mulher, de menino, até de bicho”, que "vale sutilmente como vínculo entre a inconsciência da natureza e a frouxa consciência das pessoas" (CANDIDO, 2012, p. 120).

Inácia Domingas é negra, mas, diga-se logo, assimilada. Domina o português e possui, repare bem, madrinha branca, dona de comércio, de forma que acredita: afilhada de branca, branca é. Inácia “ia se casar mas era com um branco - não com Kam'tuta -, não ia assim [como diz] atrasar a raça com mulato qualquer" (p. 56). Nascida no musseque, mas aspirando à Baixa; filha de negros devotada aos brancos; empertigada na rua e silenciosa no claustro; rainha sempre ameaçada pela escrava, é de Inácia o requinte da crueldade para com os seus. Outra "Inácia"

2 As referências a esta edição de Luuanda, daqui por diante, serão feitas apenas pelo número da página. 
também é Zuzé Sipaio, auxiliar negro do Departamento de Polícia. Simples, "sô Zuzé" ficou, expressão da semiautoridade de quem pode "pôr chicote" nos desordeiros, mas não põe. Com os opressores na formalidade, na informalidade recai entre os oprimidos, mais lúcido e, portanto, mais cindido que Inácia Domingas. Na falta de mando real, dissipa-se em desmandos, prodigalizando protocolos que carecem, porém, de respeito e rigidez.

Sô Zuzé fuma um cigarro com Xico Futa, negro forte (talvez terrorista, não se sabe), na cadeia de Luanda. Vizinho da condição de colonizado, o papagaio Jacó é bicho ranhoso, feio, piolhento, velho, fraco, depenado, "despoleirado" e, segundo seu maior adversário, Garrido Fernandes, além de tudo é mau. Jacó evita descer do galho da mandioqueira, porque os galos lhe dão "uma surra de bicadas". Não fosse Jacó papagaio de musseque, mas papagaio da Baixa, e "era diferente. (...) assobiava hino nacional e fazia toque de corneta do batalhão e tudo" (p. 58). Fosse a cadeia dos negros a mesma cadeia dos brancos, e os condenados negros não sairiam, diariamente, para varrer o chão e limpar a latrina dos condenados brancos. Fosse o musseque Lixeira, na verdade, o Sambizanga, e não haveria tanta batida policial, casa arrombada, gente arrastada sem mais para longe. Lomelino e Garrido são do sítio entre o Sambizanga e o Lixeira: "As pessoas que estão morar lá dizem é o Sambizanga; a polícia que anda patrulhar lá, que já é Lixeira, mesmo" (p. 39).

Nesta sociedade fragmentada à exaustão, as palavras de Xico Futa são terroristas:

Pode mesmo a gente saber, com a certeza, como é um caso começou, aonde começou,
por quê, pra quê, quem? (...) Ou tudo que passa na vida não pode-se-lhe agarrar no
princípio, quando chega nesse princípio vê afinal esse mesmo princípio era também
o fim doutro princípio e então, se a gente segue assim, para trás ou para frente, vê
que não pode se partir o fio da vida, mesmo que está podre nalgum lado, ele sempre
se emenda noutro sítio, cresce, desvia, foge, avança, curva, pára, esconde, aparece... (VIEIRA. 1982, p. 52).

A imagem do cajueiro (sem início e sem fim) é de ressonância clássica. Remete a seu modo à oposição, cara à modernidade desde pelo menos o século XVI, entre natureza e cultura. Apenas como menção, vale notar que nos contratualistas ingleses, mesmo Thomas 
Hobbes (para quem o "estado de natureza" era o estado da guerra permanente de todos contra todos) não deixara de caracterizar o corpo social como um monstruoso Leviatã , indicando assim seu poder coercitivo sobre o indivíduo. Ou seja, a noção de que a sociedade conspurcara, para bem ou para mal, certa condição natural da liberdade é constitutiva do imaginário ocidental moderno.

Nos árcades e, depois, nos românticos, esta idealização de uma natureza primigênia, anterior e relativamente livre das máculas da sociedade se tornou aos poucos mais aguda e complexa, imiscuindo-se na representação dos próprios colonizados. Tardiamente arcádica, tal natureza aparece no poema de José da Silva Maia Ferreira (nascido em Luanda e de passagem pelo Brasil, entre 1834 e 1845), cujos versos lembram a famosa Canção do Exílio, de Golçalves Dias: "Navega pois, meu madeiro, / Nestas águas de esmeraldas, / Vai junto do monte às faldas / Nessas praias a brilhar! / Vai mirar a natureza, / Da minha terra a beleza, / Que é singela, e sem fereza / Nesses plainos de além-mar" ${ }^{3}$. O preço a se pagar pela emulação da natureza domesticada de tipo europeu ("sem fereza”) é o sacrifício de sua forma particular e potencialmente disruptiva por algo aceitável ("singela"), no que o rio angolano assume, contraintuitivamente, as ondulações de aprazíveis serras lusitanas.

Em As Cidades e as Serras (1901), de Eça de Queiroz, surpreende-se o dado romântico (o regresso às serras portuguesas) mesclado a certo naturalismo difuso (pela comparação de cariz biológico), ao mesmo tempo em que a natureza surge como ente regenerador:"Tormes dormia no esplendor da manhã. (...) Comparei-o a uma planta estiolada (...) que, levada para vento e sol, profusamente regada, reverdece, desabrocha e honra a Natureza! Jacinto já não corcovava" (QUEIROZ, 1998, p. 139). Entretanto, se no âmbito do romantismo a natureza podia surgir como mote da exaltação nacionalista, no que concerne o domínio imperial, o testemunho europeu foi bem diferente.

Até bem entrado o século XX, a natureza em África pouco ou nada tem, por seu turno, das prazenteiras e agradáveis serras lusitanas, em que Jacinto de Tormes e seu afável amigo,

3 Esta citação, bem como algumas das primeiras representações de poetas brasileiros sobre as colônias portuguesas em África, está no texto "A presença da literatura brasileira na formação dos sistemas literários dos países africanos de língua portuguesa”, de Tânia Macedo, publicado em Revista Crioula, nº 5, maio de 2009. 
José Fernandes, buscam refúgio para recuperar a vida danificada pela faina civilizatória. Ao contrário, a imagem dessa natureza será talhada, em grande medida, por uma visão horrífica, que tem n'O Coração das Trevas, de Joseph Conrad (2009), uma de suas mais fortes expressões. Inserido no contexto imperialista, este romance (talvez não por acaso de um autor polonês) é exemplar por seu estilo seco, suas linhas categóricas e noções levadas ao paroxismo. O semblante domesticado da natureza (em espaço metropolitano) cede lugar a feições selvagens, motivo de terror por parte do europeu "civilizado". Contudo, diferente de outros, o romance de Conrad manterá seu teor de verdade porque, à medida que mergulha nas trevas do rio Congo, desautoriza o projeto imperial, denunciando a irracionalidade e a violência de seus expedientes. É uma faca de dois gumes, que previne-o de recair (como muitos recaíram) na categoria do "romance colonial", de tom panfletário. Nesse sentido, Conrad antecipa-se a seus conterrâneos: por ter presenciado o processo de acumulação capitalista nas margens indevassadas do império inglês, Conrad pôde vislumbrar com mais clareza o tipo de razão que encabeçava o chamado progresso desde a metade do século XIX.

É sob tais paradigmas (da natureza afável na Europa, por um lado, e de sua versão sombria sob o jugo colonial, por outro) que a história do cajueiro, contada por Xico Futa, reclama a imagem da natureza para dotá-la, agora, de impulso vital que não pode ser tolhido pela arbitrariedade humana. É um elogio à força da vida, que se opõe ao lastro mortífero do sistema colonial e, no interior de uma sociedade fraturada, impõe a inteireza como princípio desestabilizador. Porque recusa apreensão, o cajueiro não é natureza dócil. Porque emana vitalidade, escapa ao viço mortiço do mundo colonial. Seu quinhão romântico está amparado num realismo peculiar, que é a cosmogonia dos povos que resistem à missão civilizatória, o que lhe poupa o tom (que seria insuportável em 1960) da idealização ingênua.

Houve, portanto, uma época, não tão distante, quando homens e mulheres sabiam que outro futuro era possível e lutaram para que ele se realizasse. Esse período é aquele que vai grosso modo da década de 1940 até a de 1970 e corresponde ao que é geralmente chamado de 'descolonização'. Para a geração que viveu esse tempo 
crucial, liberdade e justiça não foram utopias. Eles pareciam ao alcance da mão ${ }^{4}$.” (BOUAMAMA, 2014, p. 6)

Sendo utópica, sua promessa não é abstrata, encarnada na personagem Xico Futa. Este, por sua vez, parece perder individualidade, tornando-se alegoria de uma cultura que, segundo o autor, viveria pujante sob o peso da máquina colonial. É Xico Futa quem articula a sabedoria e a harmonia que seguiriam imaculadas, apesar de toda a violência. Como o cajueiro, cujos limites são inapreensíveis, nada sabemos de seu passado, presente ou futuro.

\section{Ideologia colonial}

No âmbito da consciência, o traço mais forte da "Estória do Ladrão e do Papagaio" é este: tudo aquilo que é considerado "acaso" pelas personagens (o sofrimento advindo da cor da pele; da falta de amor; do incidente fatal; da perna coxa etc.) deve-se, na verdade, à extrema violência do sistema colonial português, especialmente hierarquizado e militarizado devido à baixa dinâmica econômica e social. Isso porque "no tipo mais antigo de imperialismo [marcadamente agrário e movido por um sistema vantajoso de trocas primárias], a superioridade tecnológica está confinada ao recurso externo da violência" (ANDERSON, 1966, p. 51). O único verdadeiro acaso é o fato de os comparsas do capiango (roubo, furto, crime) terem sido pegos na noite em que roubavam os patos do quintal de Ramalho da Silva; contudo, esse único acaso, dada a maneira perversa como o sistema colonial articula as relações entre todos, não é visto como acaso, mas como coisa pensada: teria sido Garrido Fernandes quem delatou o amigo Lomelino dos Reis e João-Miguel; Lomelino, por sua vez, incrimina falsamente Garrido Fernandes.

4 «Il y eut pourtant une époque, pas si lointaine, où des hommes et des femmes savaient qu'un autre avenir était possible et se battaient pour qu'il se concretise. Cette periode est celle qui va grossièrement des années 1940 aux années 1970 et qui correspond à ce qu’on appelle généralement la ‘décolonisation'. Pour la génération qui a vécu cette époque charnière, la liberté et la justice n'étaient pas des utopies. Elles semblaient à portée de main. » 
O homem [Xico Futa] tinha-lhe dado encontro logo-logo na hora que o mulato sentou no chão, desanimado, com a vontade de chorar, de pelejar com o Dosreis, uma coisa assim ele não queria aceitar o outro podia fazer, pôr um falso [uma falsa acusação]. Ainda se era verdade, aceitava; mas assim doía. (pp. 91-92)

A incriminação, além de jogar os homens uns contra os outros, acaba por desaguar em âmbito íntimo, quase familiar, que é também outra das alienações impostas pelo colonialismo à história particular de cada um, visto que as personagens são privadas constantemente dos laços de confiança e solidariedade.

- Oiça então! Um engano pode ser, sucede. Só você é que sabia o assunto ia passar. (...) O Dosreis ficou com a raiva. Julgou você é que tinha lhe queixado porque te deixaram...

- É isso mesmo! É isso eu não admito! Não é mais o falso, não senhor. Agora, uma pessoa me conhece de monandengue, pode pensar isso de mim? Pode? Diz então? Pode? (p. 92)

Eis porque se deparam na prisão logo no início do conto. O que Luandino quer nos mostrar não é, unicamente, a crueldade da razão colonial nos expedientes pelos quais os colonos brancos oprimem os angolanos e, entre estes, a grande maioria negra. $\mathrm{O}$ autor quer mostrar como essa violência está incutida nas mentes e corpos dos próprios colonizados, que a reproduzem, sendo obsoleta a presença física do colono.

Aqui, na falta da monetização dos indivíduos - porque o caráter rudimentar do sistema colonial português exclui grande parcela deles do mundo do trabalho -, a violência aparece como seu negativo, é a sombra deste "sujeito automático" e se reproduz sozinha. Mas nada disso seria possível se, ainda segundo Luandino, esses maus expedientes não emergissem invertidos na consciência, ou seja, como ideologia: o que é planejado [a arquitetura colonial que submete os dominados e os joga uns contra os outros] se torna "mero acaso" quando opta por contabilizar as infelicidades da existência; o que é mero acaso [a batida policial que, pese a vigilância sistemática, acabou por deparar com os ladrões numa noite escura] transmuta em "plano"elucubrado pelos criminosos de uma ordem criminosa. 
A tendência isolacionista que o colonialismo impõe à vida dos homens, sob hierarquia rígida e acachapante, constrange essa mesma vida a surgir sob a luz de escuros desígnios. Aplastrados como animais, aos animais se referem quando sentem necessidade de reafirmar sua condição original:

\footnotetext{
Então, quem? Cada qual era bom e mau (...). Quem era o inimigo? O Jacó? Num de repente viu o culpado, o bandido era esse bicho velho e mal-educado, mas depois até desatou a rir. Um homem como ele e o inimigo dele era um bicho, não podia! Mas a verdade é que essa ideia crescia como capim por todos os lados da cabeça e do coração. (pp. 85-86).
}

Tal como as figuras fantasmagóricas de Vidas Secas, de Graciliano Ramos, estes seres se dirigem aos animais que, por sua vez, parecem assumir estatura humana. É o jogo das proporções, que o colonialismo português recria. Jacó, o papagaio, surge como uma compensação às frustrações decorridas da impotência e da humilhação, uma porta de saída ao ar sufocante do imobilismo. Sob a perspectiva do sofrimento, Jacó é adversário real, na medida em que responde à ânsia pessoal por afirmação (ainda que violenta) da própria existência. Por outro lado, sob o viés do sistema colonial, o papagaio é outra das imagens enganadoras lançadas à consciência, remetendo simultaneamente ao amesquinhamento do ser humano e ao seu esforço de preservação. Tal preservação é sentida, ao longo do conto, pelos caminhos que a amizade e o entendimento entre as personagens desvelam, deixando crer que o embrutecimento - sentido último do poder colonial - não foi completo.

\section{Ideologia e negatividade}

A produtividade da negatividade em "Estória do ladrão e do papagaio", de Luandino Vieira, mostra-se com mais força na ausência de qualquer esforço militante, o que diferencia Luuanda de obras como A Vida Verdadeira de Domingos Xavier, do mesmo autor, ou Mayombe, de Pepetela. No Brasil, essa diferença pode ser sentida no fosso que sepa- 
ra boa parte do trabalho de Jorge Amado daquele de Graciliano Ramos, ambos também contemporâneos.

Sem apostar num viés socialista ou mesmo nacionalista, nesse conto o escritor parece amealhar suas forças numa frente única: a dos limites sociais, culturais, ideológicos e epistemológicos do projeto colonial português. Aqui, a representação da realidade se contenta, portanto, em negar a viabilidade da continuidade do império (vide a metáfora do cajueiro), no que os menores detalhes daquelas vidas decantadas ressoam como crítica acerba, e em grande escala, da inatualidade histórica do projeto colonial português em tempos de neocolonialismo nascente (ou já não tão nascente, porque Portugal é retardatário), cujos epígonos não eram mais as velhas metrópoles europeias, mas as superpotências que polarizavam o cenário da Guerra Fria. Em suma, “uma situação volátil em que a ordem internacional pós-1945 estava em plena recomposição, onde as relações de força política evoluíam constantemente e onde as configurações sociais no seio das sociedades africanas estavam em mutação acelerada. ${ }^{\text {" }}$ (BOUAMAMA, 2014, p.13).

Preservando-se de qualquer menosprezo ao papel das vanguardas nacionalistas ou comunistas no périplo pela emancipação do país, Luandino insere, porém, as tensões desse conto no processo mais amplo do jogo de forças mundiais - a saber, o conflito entre modernização retardatária e permanências arcaicas das sociedades ditas "tradicionais" - cujo desenrolar relegaria ao anacronismo, em futuro próximo, inclusive as pretensões à universalidade daquelas vanguardas (comunista, nacionalista, liberal etc.). Daí o poder duradouro de sua criação estética.

5 « (...) une situation mouvante où l'ordre international post-1945 était en pleine recomposition, où les rapports de forces politiques évoluaient constamment et où les configurations sociales au sein des sociétés africaines étaient en mutation rapide. » 


\section{Referências Bibliográficas}

ANDERSON, Perry. Portugal e o Fim do Ultracolonialismo. Rio de Janeiro: Civilização Brasileira, 1966.

BOUAMAMA, Said. Figures de la révolution africaine : De Kenyatta à Sankara. Paris: Éditions La Découverte, 2014.

CANDIDO, Antonio. Fiç̧ão e Confissão. Rio de Janeiro: Ouro sobre Azul, 2012.

CONRAD, Joseph. O coração das trevas. Trad. Luciano Alves Meira, São Paulo: Martin Claret, 2009.

MACEDO, Tânia. "A presença da literatura brasileira na formação dos sistemas literários dos países africanos de língua portuguesa”. Revista Crioula, São Paulo, nº 5, 2009.

QUEIROZ, Eça. A cidade e as serras. 2 ed. São Paulo: Ática, 1998.

VIEIRA, Luandino. Luuanda. São Paulo: Editora Ática, 1982. 